\title{
Geographic distribution of the cagA, vacA, ice $A$, oipA and dupA genes of Helicobacter pylori strains isolated in China
}

\author{
Zhijing Xue ${ }^{1 \dagger}$, Hong Yang ${ }^{2 \dagger}$, Dongxing Su ${ }^{3}$, Xiangfeng Song ${ }^{4}$, Xin Deng ${ }^{5}$, Changhong Yu ${ }^{6}$, Chunhua Sun ${ }^{7}$, \\ Lihua He ${ }^{1}$, Yuanhai You', Yanan Gong ${ }^{1}$, Dongjie Fan ${ }^{1}$, Lu Sun ${ }^{1}$, Xiurui Han ${ }^{1}$, Ruyue Fan ${ }^{1}$, Maojun Zhang ${ }^{1}$, \\ Xiaomei Yan ${ }^{1}$, Jiaming Qian ${ }^{2^{*}}$ and Jianzhong Zhang ${ }^{1 *}$ (D)
}

\begin{abstract}
Background: There are geographic variations in the genotypes of Helicobacter pylori (H. pylori) cagA, vacA, iceA, oipA and $d u p A$. The aim of the study was to investigate the distribution of these genotypes among $H$. pylori strains from five regions of China and their association with clinical outcomes.

Materials and methods: Gastric biopsy specimens were obtained from 348 patients with different gastrointestinal diseases in the five regions of China. The regional distribution was 89 patients from Shandong, 91 from Guangxi, 57 from Hunan, 58 from Qinghai and 53 from Heilongjiang. The presence of cagA, vacA, iceA, oipA and dupA genotypes was determined by polymerase chain reaction (PCR) from H. pylori DNA.

Results: A total of 269 H. pylori isolates were obtained, of which 74 isolates were from Shandong, 78 from Guangxi, 46 from Hunan, 33 from Qinghai and 38 from Heilongjiang. The cagA-positive status was predominant in the five regions. The predominant vacA genotypes were s1c (73.4\%), m2 (70.6\%) and i1 (92.9\%). In strains from Shandong, s1a and $\mathrm{m} 1$ were dominant. By contrast, s1 c was dominant in Guangxi and i1 was dominant in Hunan and Heilongjiang. The prevalence of $\mathrm{m} 2$ subtype in Qinghai (78.8\%) was significantly higher than that in other regions $(P<0.05)$. The predominant iceA genotype was iceA1 and the frequency of iceA1 was significantly more prevalent in Hunan than in other regions $(P<0.05)$. The oipA status "on" gene was more frequent in Shandong $(91.9 \%)$ and Guangxi $(91 \%)$ than in Heilongjiang (71.7\%) $(P<0.05)$. Conversely, the dupA-positive status was less than half in Shandong $(31.1 \%)$ and Guangxi (15.4\%), whereas it was 73.9\% in Hunan and $81.8 \%$ in Qinghai $(P<0.001)$. There were no significant associations between the cagA, vacA, iceA, oipA genotypes and clinical outcomes. The dupA-positive strains were more common in peptic ulcer disease (PUD) patients than in non-ulcer dyspepsia (NUD) patients in Shandong and Guangxi $(P<0.05)$, but the association was not observed in other geographic regions.
\end{abstract}

\footnotetext{
*Correspondence: qianjiaming1957@126.com; zhangjianzhong@icdc.cn

${ }^{\dagger}$ Zhijing Xue and Hong Yang contributed equally for this work

1 State Key Laboratory of Infectious Disease Prevention and Control,

Collaborative Innovation Center for Diagnosis and Treatment of Infectious

Diseases, Chinese Center for Disease Control and Prevention, National

Institute for Communicable Disease Control and Prevention, Beijing,

China

2 Peking Union Medical College Hospital, Peking Union Medical College,

Chinese Academy of Medical Sciences, Beijing, China

Full list of author information is available at the end of the article
}

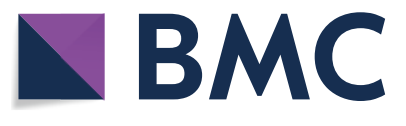

(c) The Author(s) 2021. This article is licensed under a Creative Commons Attribution 4.0 International License, which permits use, sharing, adaptation, distribution and reproduction in any medium or format, as long as you give appropriate credit to the original author(s) and the source, provide a link to the Creative Commons licence, and indicate if changes were made. The images or other third party material in this article are included in the article's Creative Commons licence, unless indicated otherwise in a credit line to the material. If material is not included in the article's Creative Commons licence and your intended use is not permitted by statutory regulation or exceeds the permitted use, you will need to obtain permission directly from the copyright holder. To view a copy of this licence, visit http://creativeco mmons.org/licenses/by/4.0/. The Creative Commons Public Domain Dedication waiver (http://creativecommons.org/publicdomain/ zero/1.0/) applies to the data made available in this article, unless otherwise stated in a credit line to the data. 
Conclusions: There was significant geographic diversity of H. pylori genotypes in different regions of China and the presence of dupA gene can be considered as a marker for the development of gastroduodenal diseases. However, the $c a g A$, iceA, vacA and oipA genes cannot be regarded for prediction of the clinical presentation of $H$. pylori infection in China.

Keywords: Helicobacter pylori, Genotype, Virulence genes, PCR, China

\section{Background}

Helicobacter pylori (H. pylori) is a chronic infectious pathogen that can lead to gastroduodenal diseases such as chronic gastritis, peptic ulcer disease (PUD), gastric carcinoma (GC) and mucosa associated lymphoid tissue (MALT) lymphoma [41]. Owing to the carcinogenicity of H. pylori, it was classified as a grade I carcinogen by the World Health Organization [3]. It has been proved that more than half of the world's population are infected with $H$. pylori and the prevalence of $H$. pylori has been declining in Western countries, whereas the prevalence has plateaued at a high level in developing countries [21]. $H$. pylori is characterized by genetic diversity, but the clinical symptoms caused by different strains are variable and considered to be related to the genetic susceptibility and living environment of the host, mainly due to the bacterial virulence factors [40].

Several $H$. pylori virulence factors, such as cagA, vacA, iceA, oipA and $\operatorname{dup} A$ have been identified to play an important role in the pathogenicity of $H$. pylori [24]. The CagA (cytotoxin-associated gene A) has been considered as an important carcinogen and cagA-positive strains can increase the risk of PUD or GC. There are EPIYA segments in the CagA C-terminal region, which are the tyrosine phosphorylation sites of CagA protein. According to the difference of the amino acid sequences flanking the EPIYA motifs, CagA $C$-terminal region can be divided into four different segments: EPIYA-A, EPIYA-B, EPIYA-C and EPIYA-D [20].

VacA (vacuolating cytotoxin A), which can induce vacuolation and multiple cellular activities, is encoded by $v a c A$ gene, which has distinct alleles [13]. Although $v a c A$ is present in all $H$. pylori strains, it shows allelic variation in three main regions: the signal (s) region (s1a, s1b and s1c, s2), the intermediate (i) region (i1 and i2) and the middle $(\mathrm{m})$ region $(\mathrm{m} 1$ and $\mathrm{m} 2)$ [37]. The different combination of $\mathrm{s}$ and $\mathrm{m}$ regions determines the production of cytotoxic activity and constitutes mosaic gene structure. Strains with the genotype $\mathrm{s} 1 \mathrm{~m} 1$ produce high levels of toxin in vitro, followed by $\mathrm{s} 1 \mathrm{~m} 2$, while $\mathrm{s} 2 \mathrm{~m} 1$ strains produce low toxicity and $\mathrm{s} 2 \mathrm{~m} 2$ strains produce little or no toxin [8]. It has been shown that $\mathrm{s} 1 \mathrm{~m} 2$ strains that contain the i1 allele are vacuolating, whereas strains that contain the i2 allele are non-vacuolating [17]. Studies have shown that $\mathrm{s} 1 \mathrm{~m} 1$ subtype is highly correlated with
PUD and GC [19, 31, 38]. Additional studies also found strains containing the $v a c A$ i1 allele can increase the risk of GC [32]. There are geographic variations in the distribution of $v a c A$ genotypes in different regions. Many researches have shown that $v a c A$ sla and s1c are predominant in Asia and northern Europe, whereas s1b is common in South America, Southern Europe and South Africa [14, 47]. These differences may lead to diversity in prevalence of gastroduodenal diseases in different geographic regions.

The iceA (induced by contact with epithelium) has two main allelic variants: $i c e A 1$ and ice $A 2$, which also has a particular geographic distribution [22]. The iceA1 was common in Japan and Korea while the iceA2 was predominant in the America, Colombia and Europe [35]. The OipA (outer inflammatory protein A) increases inflammatory response by affecting interleukin 8 (IL-8) production. The oipA functional status is regulated by slipped-strand mispairing that is based on the number of CT dinucleotide repeats in the signal sequences of the gene (switch "on" = functional and switch "off"=nonfunctional) [45]. Studies have shown that the prevalence of oipA in duodenal ulcer (DU) and GC is higher, suggesting that oipA is not only associated with inflammation, but also the development of GC [46]. The dupA (duodenal ulcer promoting gene A), first recognized as a marker of $H$. pylori specific disease, can induce DU and inhibit GC [2].

China is a country with large population, wide area and high incidence of $H$. pylori infection. In addition, the incidence rate of GC in China is higher than that in the Western countries. Heilongjiang and Qinghai provinces are high risk areas of GC, which are located in the northeast and northwest of China respectively, the mortality rate of GC ranges from 40 to 70 per 100,000 persons, compared to 10 to 20 per 100,000 persons in Guangxi and Hunan, low risk areas of GC, which are located in the South and Central South of China respectively [10]. Shandong province is located in the east of China and the crude mortality rate of GC was 49 per 100,000 persons, accounting for $21 \%$ of all malignant cancers [28]. At present, there are many studies focusing on the relationship between $H$. pylori virulence factors and clinical outcomes in China. However, only a few studies regarded information on the relationship between $H$. pylori virulence genotypes and 
different geographic regions. We therefore investigated the distribution of $v a c A, \operatorname{cag} A$, ice A, oipA and $\operatorname{dupA}$ genotypes in different regions of China and their association with clinical outcomes.

\section{Results}

A total of $269 \mathrm{H}$. pylori isolates out of 348 gastric biopsy specimens from five geographic regions of China were obtained, of which 74 isolates were from Shandong, 78 from Guangxi, 46 from Hunan, 33 from Qinghai and 38 from Heilongjiang. At endoscopy 21 patients presented with PUD. The remaining 248 patients were diagnosed as having non-ulcer dyspepsia (NUD). No patients with $\mathrm{GC}$ were included in the study. $H$. pylori virulence genes cagA, vacA, iceA, oipA and dupA were detected by polymerase chain reaction (PCR) in all isolates and H. pylori genotypes results were summarized in Table 1 .

\section{cagA genotypes}

Overall, 261(97\%) patients were infected with cagApositive strains (Table 1). Of these cagA-positive strains, 70(94.6\%) strains were isolated from Shandong, 74
(94.9\%) from Guangxi, 100\% from Hunan, Qinghai and Heilongjiang. $96.6 \%(252 / 261)$ of the cagA genes detected were East Asian type, whereas only 9 strains were Western type. 55.6\% (5/9) Western strains were from Heilongjiang and there was a significant correlation between the type $\mathrm{ABC}$ and Heilongjiang isolates $\left(\mathrm{X}^{2}=15.512\right.$, $\mathrm{P}<0.01)$. The distribution of $\mathrm{CagA}$ sequence types was shown in Table 2. There were 2-4 EPIYA motifs in CagA C-terminus, and $94.3 \%[(238+8) / 261]$ of the strain sequences had three EPIYA segments. There were obvious differences between segment EPIYA-C and EPIYA-D when analyzed using the WebLogo 3 (Fig. 1).

The phylogenetic tree was constructed from cagA 3' variable region sequences. As shown in the Additional file 1 , the phylogenetic tree diverged into two lineages. In the lineage one, H. pylori 26695 was clustered with 9 Western type strains from different regions. In the second lineage, H. pylori GZ27 was clustered with East Asian strains from five regions. The phylogenetic analysis did not reveal any association between a particular disease and a specific cagA sequence. The cagA gene was present in $97.2 \%$ and $95.2 \%$ of $H$. pylori strains isolated

Table 1 Distribution of virulence genotypes among 269 H. pylori-positive patients with different geographic regions

\begin{tabular}{|c|c|c|c|c|c|c|}
\hline \multirow[t]{2}{*}{ Genetypes } & \multicolumn{6}{|c|}{ No. of isolates } \\
\hline & $S D(n=74)$ & $G X(n=78)$ & $\mathrm{HN}(\mathrm{n}=46)$ & $\mathrm{QH}(\mathrm{n}=33)$ & $H L(n=38)$ & Total $(n=269)$ \\
\hline $\operatorname{cag} A$ & 70(94.6) & 74(94.9) & $46(100)$ & $33(100)$ & $38(100)$ & 261(97) \\
\hline \multicolumn{7}{|l|}{$\operatorname{vac} A$} \\
\hline s1 & $72(97.3)$ & $78(100)$ & 45(97.8) & 30(90.9) & $38(100)$ & 263(97.8) \\
\hline s2 & $2(2.7)$ & 0 & $1(2.2)$ & $3(9.1)$ & 0 & $6(2.2)$ \\
\hline $\mathrm{m} 1$ & $30(40.5)$ & 14(17.9) & $10(21.7)$ & $6(18.2)$ & 12(31.6) & $72(26.8)$ \\
\hline $\mathrm{m} 2$ & $43(58.1)$ & $61(78.2)$ & $35(76.1)$ & $26(78.8)$ & $25(65.8)$ & 190(70.6) \\
\hline ¡1 & $66(89.2)$ & $71(91)$ & $46(100)$ & $29(87.9)$ & $38(100)$ & 250(92.9) \\
\hline$i 2$ & $8(10.8)$ & $7(9)$ & 0 & $4(12.1)$ & 0 & 19(7.1) \\
\hline s1i1m1 & $22(29.7)$ & $12(15.4)$ & $10(21.7)$ & $6(18.2)$ & 12(31.6) & $62(23)$ \\
\hline s1i1m2 & $42(56.8)$ & $53(67.9)$ & $34(73.9)$ & $22(66.7)$ & $25(65.8)$ & $176(65.4)$ \\
\hline $\mathrm{s} 1 \mathrm{i} 2 \mathrm{~m} 1$ & $7(9.6)$ & $2(2.6)$ & 0 & 0 & 0 & $9(3.3)$ \\
\hline $\mathrm{s} 1 \mathrm{i} 2 \mathrm{~m} 2$ & 0 & $5(6.4)$ & 0 & $1(3)$ & 0 & $6(2.2)$ \\
\hline s2i1m1 & 0 & 0 & 0 & 0 & 0 & 0 \\
\hline s2i1m2 & $1(1.4)$ & 0 & $1(2.2)$ & 0 & 0 & $2(0.7)$ \\
\hline $\mathrm{s} 2 \mathrm{i} 2 \mathrm{~m} 1$ & $1(1.4)$ & 0 & 0 & 0 & 0 & $1(0.4)$ \\
\hline $\mathrm{s} 2 \mathrm{i} 2 \mathrm{~m} 2$ & 0 & 0 & 0 & $3(9.1)$ & 0 & $3(1.1)$ \\
\hline iceA1 & $49(66.2)$ & $50(64.1)$ & $38(82.6)$ & $24(72.7)$ & $26(68.4)$ & $187(69.5)$ \\
\hline iceA2 & $12(16.2)$ & $20(25.6)$ & $8(17.4)$ & $6(18.2)$ & $8(21.1)$ & $54(20.1)$ \\
\hline oipA"on" & 68(91.9) & $71(91)$ & $41(89.1)$ & $30(90.9)$ & $27(71.1)$ & $237(88.1)$ \\
\hline oipA"off" & $3(4.1)$ & $2(2.6)$ & 0 & 0 & 0 & $5(1.9)$ \\
\hline dupA & 23(31.1) & $12(15.4)$ & $34(73.9)$ & $27(81.8)$ & $25(65.8)$ & $121(45)$ \\
\hline
\end{tabular}

Isolates were from five regions of China: Shandong (SD), Guangxi (GX), Hunan (HN), Qinghai (QH) and Heilongjiang (HL) 
Table 2 Distribution of CagA sequence types in different geographic regions of China

\begin{tabular}{|c|c|c|c|c|c|c|}
\hline \multirow[t]{2}{*}{ Regions } & \multicolumn{5}{|c|}{ CagA sequence types } & \multirow[t]{2}{*}{ Total } \\
\hline & $A B$ & $A B D$ & AABD & $A B C$ & $A B C C$ & \\
\hline SD & 9 & 59 & 1 & 1 & 0 & 70 \\
\hline GX & 0 & 71 & 1 & 1 & 1 & 74 \\
\hline $\mathrm{HN}$ & 0 & 46 & 0 & 0 & 0 & 46 \\
\hline $\mathrm{QH}$ & 0 & 32 & 0 & 1 & 0 & 33 \\
\hline $\mathrm{HL}$ & 3 & 30 & 0 & 5 & 0 & 38 \\
\hline Total & $12(4.6)$ & 238(91.2) & $2(0.8)$ & $8(3)$ & $1(0.4)$ & 261 \\
\hline
\end{tabular}

Isolates were from five regions of China: Shandong (SD), Guangxi (GX), Hunan (HN), Qinghai (QH) and Heilongjiang (HL)

Number in boldface type indicates a significant difference compared with other regions

(A) CagA EPIYA-A segment

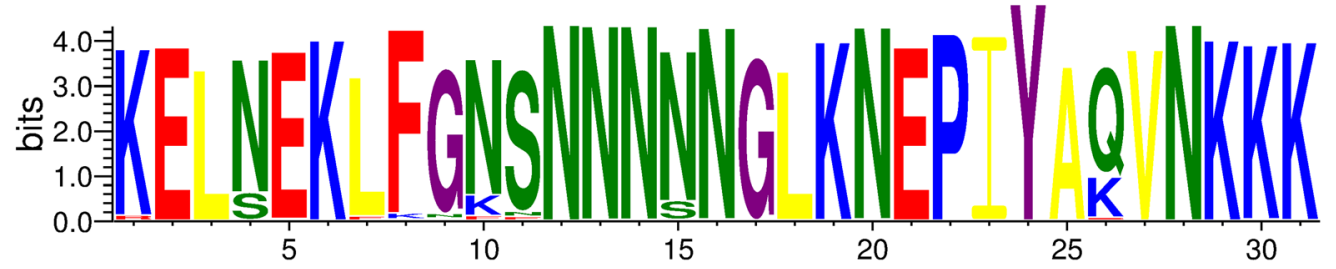

(B) CagA EPIYA-B segment

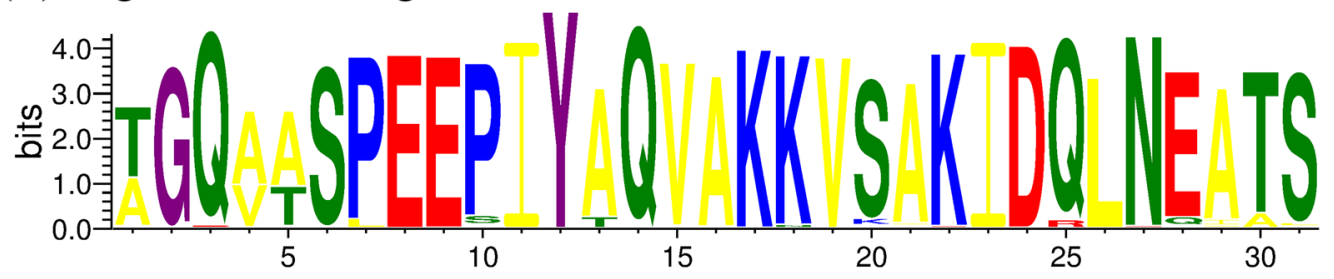

(C) CagA EPIYA-C segment

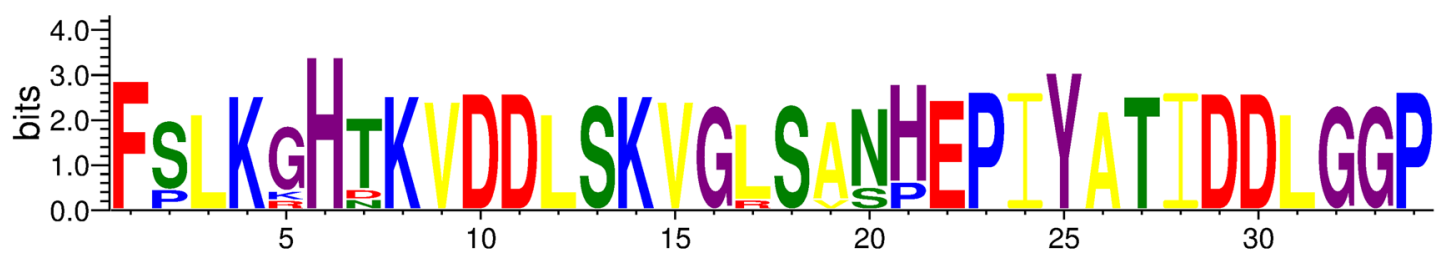

(D) CagA EPIYA-D segment

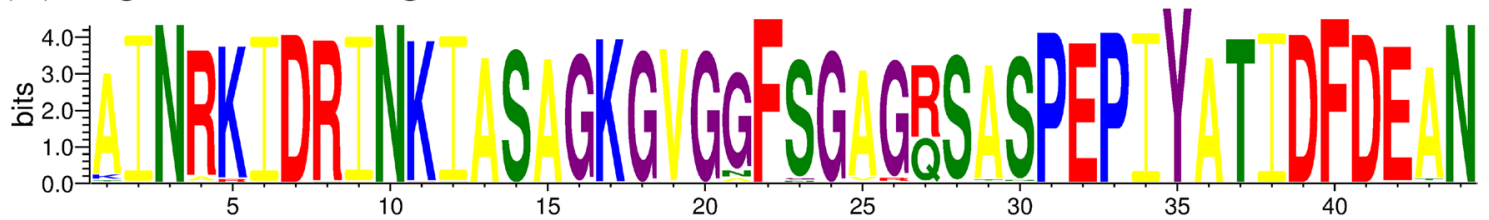

Fig. 1 EPIYA segment types in East Asian-type and Western-type CagA from Chinese strains 
Table 3 Frequency of 269 H. pylori virulence genotypes in patients with NUD and PUD

\begin{tabular}{|c|c|c|c|c|c|c|c|c|c|c|c|c|}
\hline \multirow[t]{3}{*}{ Genetypes } & \multicolumn{12}{|c|}{ No. of isolates } \\
\hline & \multicolumn{2}{|c|}{$S D(n=74)$} & \multicolumn{2}{|c|}{$G X(n=78)$} & \multicolumn{2}{|c|}{$H N(n=46)$} & \multicolumn{2}{|c|}{$\mathrm{QH}(\mathrm{n}=33)$} & \multicolumn{2}{|c|}{$H L(n=38)$} & \multicolumn{2}{|c|}{ Total $(n=269)$} \\
\hline & NUD (61) & PUD (13) & NUD (75) & PUD (3) & NUD (42) & PUD (4) & NUD (32) & PUD (1) & NUD (38) & PUD (0) & NUD (248) & PUD (21) \\
\hline $\operatorname{cag} A$ & $58(95.1)$ & 12(92.3) & $71(94.7)$ & $3(100)$ & $42(100)$ & $4(100)$ & $32(100)$ & $1(100)$ & $38(100)$ & 0 & $241(97.2)$ & $20(95.2)$ \\
\hline \multicolumn{13}{|l|}{$\operatorname{vac} A$} \\
\hline s1 & $60(98.4)$ & $12(92.3)$ & $75(100)$ & $3(100)$ & $41(97.6)$ & $4(100)$ & $30(93.8)$ & 0 & $38(100)$ & 0 & 244(98.4) & 19(90.5) \\
\hline s2 & $1(1.6)$ & $1(7.7)$ & 0 & 0 & $1(2.4)$ & 0 & $2(6.6)$ & $1(100)$ & 0 & 0 & $4(1.6)$ & $2(9.5)$ \\
\hline m1 & $26(42.6)$ & $4(30.8)$ & 13(17.3) & $1(33.3)$ & $10(23.8)$ & 0 & $6(18.8)$ & 0 & 12(31.6) & 0 & $67(27)$ & $5(23.8)$ \\
\hline m2 & $34(55.7)$ & $9(69.2)$ & 59(78.7) & $2(66.7)$ & $31(73.8)$ & $4(100)$ & $25(78.1)$ & $1(100)$ & 25(65.8) & 0 & 174(70.2) & 16(76.2) \\
\hline ¡1 & 56(91.8) & 10(76.9) & 68(90.7) & $3(100)$ & $42(100)$ & $4(100)$ & 29(90.6) & 0 & $38(100)$ & 0 & 233(94) & $17(81)$ \\
\hline i2 & $5(8.2)$ & $3(23.1)$ & $7(9.3)$ & 0 & 0 & 0 & $3(9.4)$ & $1(100)$ & 0 & 0 & $15(6)$ & $4(19)$ \\
\hline s1i1m1 & $21(34.4)$ & $1(7.7)$ & $11(14.7)$ & $1(33.3)$ & 10(23.8) & 0 & $6(18.8)$ & 0 & 12(31.6) & 0 & $60(24.2)$ & $2(9.5)$ \\
\hline s1i1m2 & $33(54.1)$ & $9(69.2)$ & $51(68)$ & $2(66.7)$ & $30(71.4)$ & $4(100)$ & $22(68.8)$ & 0 & $25(65.8)$ & 0 & $161(64.9)$ & $15(71.4)$ \\
\hline s1i2m1 & $5(8.2)$ & $2(15.4)$ & $2(2.7)$ & 0 & 0 & 0 & 0 & 0 & 0 & 0 & $7(2.8)$ & $2(9.5)$ \\
\hline s1i2m2 & 0 & 0 & $5(6.7)$ & 0 & 0 & 0 & $1(3.1)$ & 0 & 0 & 0 & $6(2.4)$ & 0 \\
\hline s2i1m1 & 0 & 0 & 0 & 0 & 0 & 0 & 0 & 0 & 0 & 0 & 0 & 0 \\
\hline $\mathrm{s} 2 \mathrm{i} 1 \mathrm{~m} 2$ & $1(1.6)$ & 0 & 0 & 0 & $1(2.4)$ & 0 & 0 & 0 & 0 & 0 & $2(0.8)$ & 0 \\
\hline $\mathrm{s} 2 \mathrm{i} 2 \mathrm{~m} 1$ & 0 & $1(7.7)$ & 0 & 0 & 0 & 0 & 0 & 0 & 0 & 0 & 0 & $1(4.8)$ \\
\hline $\mathrm{s} 2 \mathrm{i} 2 \mathrm{~m} 2$ & 0 & 0 & 0 & 0 & 0 & 0 & $3(9.4)$ & 0 & 0 & 0 & 0 & 0 \\
\hline iceAl & $40(65.6)$ & $9(69.2)$ & $48(64)$ & $2(66.7)$ & 35(83.3) & $3(75)$ & 23(69.7) & $1(100)$ & $26(68.4)$ & 0 & $172(69.4)$ & $15(71.4)$ \\
\hline iceA2 & $9(14.8)$ & $3(23.1)$ & 19(25.3) & $1(33.3)$ & $7(16.7)$ & $1(25)$ & $6(18.2)$ & 0 & $8(21.1)$ & 0 & 49(19.8) & $5(23.8)$ \\
\hline oipA"on" & $55(90.2)$ & $13(100)$ & 68(90.7) & $3(100)$ & $37(88.1)$ & $4(100)$ & 29(87.9) & $1(100)$ & $27(71.1)$ & 0 & $216(87.1)$ & $21(100)$ \\
\hline oipA"off" & $3(4.9)$ & 0 & $2(2.7)$ & 0 & 0 & 0 & 0 & 0 & 0 & 0 & $5(2)$ & 0 \\
\hline $\operatorname{dup} A$ & $15(24.6)$ & $8(61.5)$ & $10(13.3)$ & $2(66.7)$ & $32(76.2)$ & $2(50)$ & $26(78.8)$ & $1(100)$ & $25(65.8)$ & 0 & $108(43.5)$ & $13(61.9)$ \\
\hline
\end{tabular}

Isolates were from five regions of China: Shandong (SD), Guangxi (GX), Hunan (HN), Qinghai (QH) and Heilongjiang (HL)

Values in parentheses are percentages

Numbers in boldface type indicate a significant difference compared clinical outcomes (NUD and PUD) in each geographic region group with respect to $H$. pylori genotype

from patients with NUD and PUD, respectively (Table 3). There was no statistical difference between the $\operatorname{cag} A$ genotypes and clinical outcomes irrespective of the different geographic regions $\left(\chi^{2}=0.669, \mathrm{P}>0.05\right)$.

\section{vacA subtypes}

The most common vacA s region genotype was s1 (97.8\%): 97.3\% of strains from Shandong, 97.8\% from Hunan, 90.9\% from Qinghai, 100\% from Guangxi and Heilongjiang. Regardless of geographic origins and clinical outcomes, most of the vacA s1 strains were of the s1c subtype (73.4\%), while the s1a subtype was detected in $70(26.6 \%)$ and the s1b subtype was not detected in our study (Table 1; Fig. 2). The prevalence of s1a in the isolates from Shandong was $40.3 \%$, significantly higher $\left(\mathrm{X}^{2}=15.930, \mathrm{P}<0.01\right)$ than that in Guangxi $(12.8 \%)$, Hunan (33.3\%), Qinghai (30\%) and Heilongjiang (18.4\%). Conversely, the s1c subtype was significantly $\left(X^{2}=19.806\right.$, $\mathrm{P}<0.01)$ more frequent in isolates from Guangxi $(87.2 \%)$ than the other four regions. For the $v a c A$ m region, 190 patients $(70.6 \%)$ were infected with $\mathrm{m} 2$ strains and 72 (26.8\%) were infected with $\mathrm{m} 1$ strains. The frequency of the $\mathrm{m} 2$ subtype in Qinghai (78.8\%) was significantly higher $\left(x^{2}=9.900, P<0.05\right)$ than in Shandong $(58.1 \%)$. In contrast, the frequency of $\mathrm{m} 1$ subtype in Shandong $(40.5 \%)$ was significantly higher $\left(\mathrm{X}^{2}=12.539, \mathrm{P}<0.05\right)$ than the other four regions. All the $H$. pylori-infected patients were successfully detected for the $v a c A$ i region, in which $250(92.9 \%)$ patients were infected with i1 strains, while the remaining 19 (7.1\%) patients were infected with i2 strains (Table 1). The prevalence of i1 allele was significantly higher $\left(X^{2}=9.687, P<0.05\right)$ in Hunan and Heilongjiang than in other regions. We also examined the different combinations of $v a c A \mathrm{~s}, \mathrm{~m}$ and $\mathrm{i}$ alleles in patients. The dominant $v a c A$ subtype combination was s1ilm2 (65.4\%) in the five regions, but no statistical significance was noted $\left(\chi^{2}=4.168, P>0.05\right)$. There were also no statistical differences between the $v a c A$ subtypes and clinical outcomes (Table 3). 


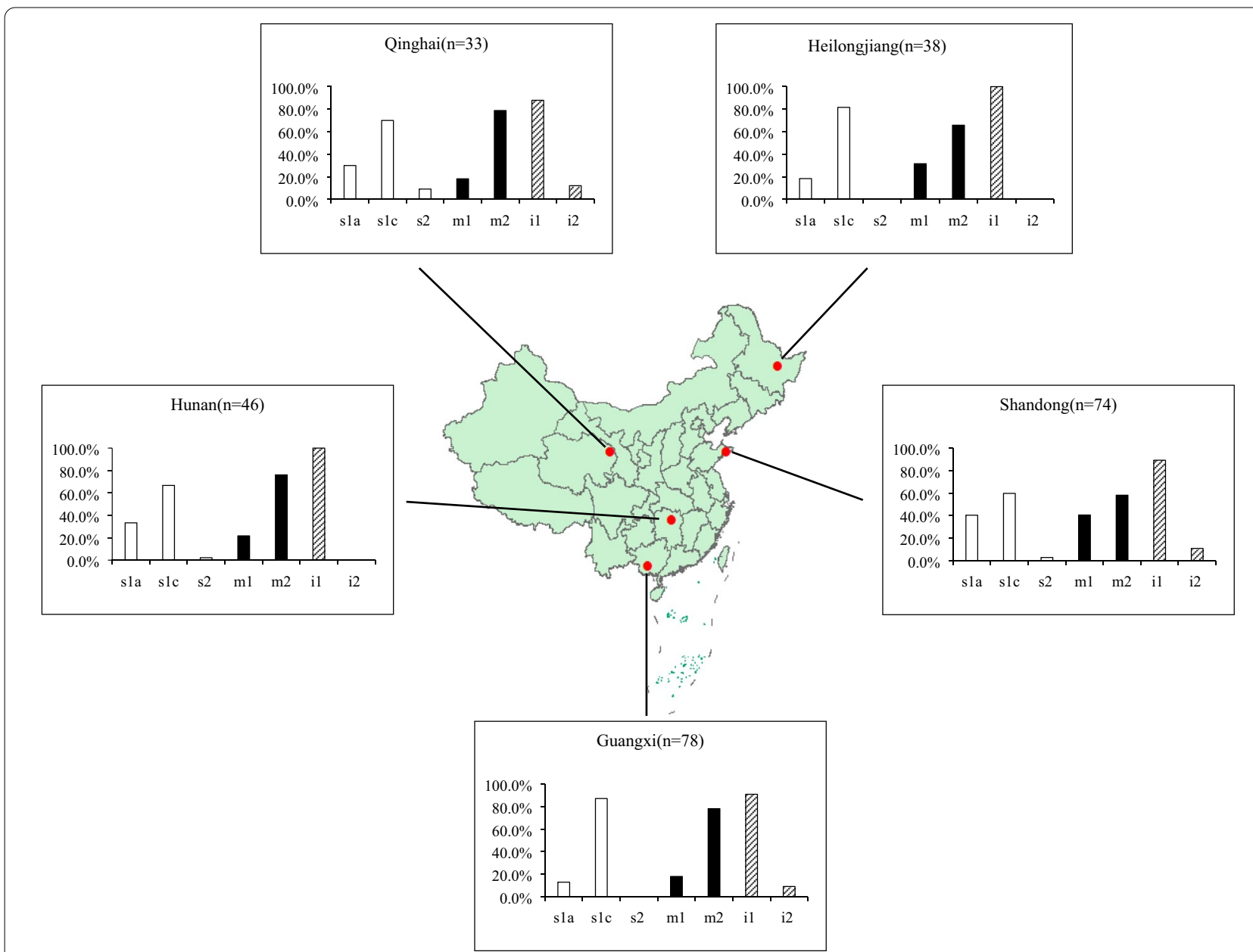

Fig. 2 Distribution of vacA s, $m$ and i region genotypes of H. pylori strains from different regions of China. The prevalence of each type (s1a, s1c, s2, $\mathrm{m} 1, \mathrm{~m} 2, \mathrm{i} 1$ and $\mathrm{i}$ ) is given as a percentage of the total number of strains (shown in parentheses)

\section{iceA status}

Overall, iceA1 was detected in 187 (69.5\%) of all 269 isolates examined and iceA2 was found in 54 isolates (20.1\%) (Table 1 ). The iceA1 frequency was significantly more prevalent in Hunan (82.6\%) than in the other four regions $\left(\mathrm{X}^{2}=11.358, \mathrm{P}<0.05\right)$. The iceA2 was present in $25.6 \%$ and $21.1 \%$ of $H$. pylori strains isolated from Guangxi and Heilongjiang, respectively, whereas only $16.2 \%$ of isolates from Shandong were infected with iceA2-positive strains. However, the difference was not statistically significant $\left(X^{2}=3.204, P>0.05\right)$. There was also no association between the iceA status and clinical outcomes in the five regions of China (Table 3).

\section{oipA status}

242 (90\%) isolates were positive with oipA set primers, and, overall, $88.1 \%$ had a functional status "on" (Table 1 ). A total of 10 oipA CT repeat patterns were identified (Table 4). The pattern containing $(3+1)$ CT repeats was the most frequently associated with the "on" status $(125 / 237,52.7 \%)$, and the pattern with 5 CT repeats was the most prevalent for a nonfunctional ("off") oipA gene $(3 / 5,60 \%)$. The oipA functional status "on" was more prevalent in Shandong isolates than in Heilongjiang isolates $\left(\chi^{2}=8.060, \mathrm{P}<0.05\right)$. Overall, $87.1 \%$ of NUD patients and $100 \%$ of PUD patients were infected with oipA functional status "on" strains, the difference was not statistically significant $\left(x^{2}=3.561, P>0.05\right)$ (Table 3$)$. When the analyses were carried out in each geographic region, the differences were also not statistically significant.

\section{dupA status}

121 (45\%) patients were infected with dupA-positive strains (Table 1). The dupA-positive strains were present in $73.9 \%$ of Hunan, $81.8 \%$ of Qinghai and $65.8 \%$ of Heilongjiang. In contrast, only $31.1 \%$ of Shandong and $15.4 \%$ of Guangxi strains were infected with $\operatorname{dupA-positive~} H$. pylori $\left(\mathrm{X}^{2}=72.497, \mathrm{P}<0.001\right)$. Overall, $43.5 \%$ of patients 
Table 4 Frequency of the oipA CT repeat patterns

\begin{tabular}{|c|c|c|}
\hline Sequence of signal peptide encoding region of oipA & No. of CT & No. of isolates \\
\hline \multicolumn{3}{|l|}{ "On" status } \\
\hline ATGAAAAAAGCTCTCTTACTAACTCTCTTTTTCTCGTTTTGGCTCCACGCTGAA & $3+1$ & 125 \\
\hline \multicolumn{3}{|l|}{ MKKALLLTLFFSFWLHAE } \\
\hline ATGAAAAAAACCCTTTTAACTCTTTCTGTCTTTCTCGTTTTGGCTCCACGCTGAA & $2+1+1$ & 82 \\
\hline \multicolumn{3}{|l|}{ MKKTLLLFLSFSFWLHAE } \\
\hline ATGAAAAAAGCTCTCTTACTAACTCTCTTTCTCTCGTTTTGGCTCCACGCTGAA & $3+2$ & 14 \\
\hline \multicolumn{3}{|l|}{ MKKALLLTLFLSFWLHAE } \\
\hline ATGAAAAAAACCCTTTTACTCACTCTTTCTCTCTCGTTTTGGCTCCACGCTGAA & $2+3$ & 1 \\
\hline \multicolumn{3}{|l|}{ MKKTLLLTLSLSFWLHAE } \\
\hline ATGAAAAAAACCCTTTTAACTCTTTCTGTCTCTCTCGTTTTGGCTCCACGCTGAA & $1+3$ & 5 \\
\hline \multicolumn{3}{|l|}{ MKKTLLLFLSLSFWLHAE } \\
\hline ATGAAAAAAGCTCTCTTACTAATTCTCTTTTTCTCGTTTTGGCTCCACGCTGAA & $2+1$ & 1 \\
\hline \multicolumn{3}{|l|}{ MKKALLLILFFSFWLHAE } \\
\hline ATGAAAAAAGCTCTCTTACTAACTCTCTCTCTCTCGTTCTGGCTCCACGCTGAA & 6 & 9 \\
\hline \multicolumn{3}{|l|}{ MKKALLLTLSLSFWLHAE } \\
\hline \multicolumn{3}{|l|}{ "Off" status } \\
\hline ATGAAAAAAGCTCTCTTACTAACTCTCTCTCTCGTTTTGGCTCCACGCTGA & 5 & 3 \\
\hline \multicolumn{3}{|l|}{ MKKALLLTLSLVLAPR* } \\
\hline ATGAAAAAAGCTCTCTTACTCTCTCTCTCTCTCGTTCTGGCTCCATGCTGA & 7 & 1 \\
\hline \multicolumn{3}{|l|}{ MKKALLLSLSLVLAPC* } \\
\hline ATGAAAAAAGCTCTCTTACTAACTCTCTCTCTCTCTCTCGTTTTGGCTCCACGCTGA & 8 & 1 \\
\hline MKKALLLTLSLSLVLAPR* & & \\
\hline
\end{tabular}

The underline represents the sequences of oip $A C T$ repeat patterns

*Indicates stop codon

with NUD and $61.9 \%$ of those with PUD were infected with dupA-positive strains (Table 3). The dupA-positive strains were significantly more common in PUD patients than in NUD patients in Shandong $\left(X^{2}=6.830, P<0.01\right)$ and Guangxi $\left(\mathrm{X}^{2}=4.254, \mathrm{P}<0.05\right)$. In contrast, the dupApositive strains were more common in NUD patients (76.2\%) than in PUD patients $(50 \%)$ in Hunan, but the difference was not statistically significant $\left(X^{2}=1.299\right.$, $\mathrm{P}>0.05)$.

\section{Discussion}

\section{Geographic distribution versus genotypes}

The present study investigated the cagA, vacA, iceA, oipA and $\operatorname{dup} A$ genotypes of $H$. pylori isolated from patients living in different geographic regions of China. Our study demonstrated that there was obvious geographic diversity of $H$. pylori genotypes in China, emphasizing that even within a country genetic diversity still existed. There are at least two reasons for the difference in $H$. pylori strains among different geographic regions. One is the accumulation of mutations in $H$. pylori strains in different regions, and the other is that there may be adaptive evolutionary selection between $H$. pylori strains and their hosts.
In China, more than $90 \%$ of $H$. pylori strains carry cagA gene, which may be the reason why the incidence rate of GC in China is higher than that in Western countries. In the present study, 97\% patients were infected with cagApositive strains. This result was similar to studies in other Asian countries and some regions of China where the prevalence of cagA-positive strains was above $90 \%$ ([34, 48]. However, this was different from reports in some European and American countries where the prevalence of cagA-positive strains ranged from 50 to $70 \%$ [15]. Furthermore, we found that the majority of CagA types were East Asian type, only 3.4\% were Western type. Some studies have shown that Western type CagA was the most frequent type in Mongolian and Russia patients and all $H$. pylori strains from GC patients possessed Western type CagA [36, 42]. In our study, 55.6\% (5/9) of the Western CagAs were from Heilongjiang, which may be due to human migration or direct transmission.

In the present study, there was a high prevalence of s1c $73.4 \%$ in the $v a c A$-positive strains, similar to previous study in other regions of China [43]. However, the result was slightly different from some reports in which the prevalence of s1c was a little lower $[14,43]$. The $v a c A \mathrm{~s} 1 \mathrm{~b}$ was not detected in our study, whereas the prevalence 
of s1b subtype was almost $100 \%$ in South America, $80 \%$ in Spain and Portugal strains, very few in East Asia [14]. The vacA s2 was prevalent in Africa and consistent with studies in some European and American countries [5, 14 ], but the $\mathrm{s} 2$ detected in this study was very low, further revealing the geographic diversity of $v a c A$ gene. The presence of vacA $\mathrm{m} 1$ strains was significantly higher in Shandong, which may be the reason for the high incidence of gastric cancer. These findings were different from some countries such as Japan, Korean, Singapore and some European and American strains [14, 47, 50], suggesting the differences between Chinese and foreign strains. In the $v a c A$ i region, the i1 subtype was dominant in the five regions and this result was consistent with those of studies that include patients from some countries, such as Japan and South Korea, where the prevalence of i1 subtype was over $95 \%[12,26]$.

The prevalence of iceA1 was $69.5 \%$ in our study, consistent with studies reported from Thailand and Korea $[11,27]$. The oipA status was regulated by strip strand repairing based on the number of $\mathrm{CT}$ nucleotide repeats in the signal sequences. The present study revealed a high prevalence of strains with oipA status "on" genes (88.1\%) regardless of the geographic origins and clinical outcomes, which was similar to previous studies [49]. The presence of $d u p A$ gene was different in distinct geographic regions, such as $84.8 \%$ in the South Africa, $43.7 \%$ in the Belgium and $70 \%$ in the United States [4]. Similarly, in the present study, the prevalence of the $d u p A$ was also different in distinct geographic regions of China. We detected $81.8 \%$ dupA-positive isolates in Qinghai, while the lower prevalence of $\operatorname{dup} A(15.4 \%)$ was in Guangxi and $31.1 \%$ in Shandong. The reasons for the difference in prevalence of $d u p A$ gene in the five geographic regions of China are unclear.

\section{Clinical outcome versus genotypes}

The present study did not reveal any associations between the $\operatorname{cag} A, v a c A$, ice $A$ and oipA genotypes and clinical outcomes. These results were consistent with other reports from China [43, 44], but was different from many studies in Western countries [7]. One important reason for the difference might be due to large genomic difference of the H. pylori. Some researchers considered that the ice $A 1$ was more common in patients with PUD while the ice $A 2$ was most frequently isolated from NUD patients $[18,33]$. However, our study showed that the presence of the ice $A$ gene was not associated with clinical outcomes. OipA is an important outer membrane protein that is closely related to severe inflammatory response and the induction of IL-8 secretion. Studies showed that the oipA status "on" was expressed in most strains isolated from patients with PUD, suggesting that it could be helpful in predicting the clinical presentation of $H$. pylori infection in different regions [46]. In this study, the presence of oipA status "on" had no correlation with clinical outcomes. Other outer membrane proteins, such as BabA, SabA and HomB, widely exist in different strains, which might play a vital role in the pathogenesis of $H$. pylori [1]. These virulence factors need further study.

Surprisingly, the $\operatorname{dupA-positive~strains~were~signifi-~}$ cantly more common in PUD patients than in NUD patients in Shandong and Guangxi $(\mathrm{P}<0.05)$. The results were different from previous studies in which there was no association between the presence of $d u p A$ and clinical diseases [39]. Conversely, the prevalence of the $d u p A$ positive strains was more common in NUD patients (76.2\%) than in PUD patients (50\%) in Hunan, but the difference was not statistically significant. Therefore, further molecular epidemiology researches in other populations will help to study the association between $\operatorname{dup} A$ gene and clinical outcomes.

\section{Conclusions}

The present study investigated the distribution of $H$. pylori virulence genotypes in five regions of China and their association with clinical outcomes. There was a reverse correlation between the $\operatorname{dup} A$ gene and PUD. However, we could not reveal clear associations of the $\operatorname{cag} A$, iceA, oipA and vacA genotypes with clinical outcomes in any of the studied regions.

\section{Materials and methods Study subjects}

A total of 348 patients were involved in this study including 89 patients from Rushan People's Hospital (Weihai, Shandong Province, China), 91 from the Second Nanning People's Hospital (Nanning, Guangxi Province, China), 57 from Yiyang Central Hospital (Yiyang, Hunan Province, China), 58 from the People's Hospital of Huzhu Tu Ethnic Autonomous County (Haidong, Qinghai Province, China) and 53 from The First Affiliated Hospital of Jiamusi University (Jiamusi, Heilongjiang Province, China). Their gastric biopsy specimens were obtained during upper gastrointestinal endoscopy with informed consent. This study was approved by Ethical Committee of National Institute for Communicable Disease Control and Prevention Chinese Center for Disease Control and Prevention (approval No. ICDC-2013001).

\section{H. pylori culture and DNA extraction}

Gastric biopsy specimens were homogenized thoroughly in brain heart infusion (BHI) broth and then streaked onto the Karmali blood agar base plates under a 
biological safety cabinet (Thermo Scientific). The Karmali Agar base (Oxoid, CM 0935) was supplemented with $5 \%$ defibrinated sheep blood and $1 \%$ combined antibiotics comprising of trimethoprim $(150 \mathrm{mg} / \mathrm{L})$, vancomycin $(125 \mathrm{mg} / \mathrm{L})$, amphotericin $\mathrm{B}(100 \mathrm{mg} / \mathrm{L})$ and polymyxin B $(100 \mathrm{mg} / \mathrm{L})$. The plates were incubated at $37^{\circ} \mathrm{C}$ under microaerobic conditions $\left(5 \% \mathrm{O}_{2}, 10 \% \mathrm{CO}_{2}\right.$ and $\left.85 \% \mathrm{~N}_{2}\right)$ for 3-5 days. H. pylori colonies were identified according to its morphological characteristics, negative Gram staining and positive for catalase, oxidase, and urease. The identified $H$. pylori was subcultured to single colonies and then preserved in sterile BHI broth with $20 \%$ glycerol and frozen at $-80{ }^{\circ} \mathrm{C}$ until the genomic DNA was extracted with the QIAamp DNA Mini Kit (Qiagen, Germany) according to the manufacturer's instructions. The extracted DNA was stored at $-20^{\circ} \mathrm{C}$ and used directly for PCR.

\section{PCR amplification}

The PCR reaction was carried out in a total volume of $25 \mu \mathrm{L}$ containing forward and reverse primers $(0.2 \mu \mathrm{M}$ each), $2 \mathrm{ng} / \mu \mathrm{L}$ DNA template, $12.5 \mu \mathrm{L}$ Go Taq ${ }^{\circledR}$ Green Master Mix (Promega, USA) and $9.5 \mu \mathrm{L}$ nuclease-free water. The amplification was as follows: initial denaturation at $94{ }^{\circ} \mathrm{C}$ for $5 \mathrm{~min}$ and then denaturation at $94{ }^{\circ} \mathrm{C}$ for $30 \mathrm{~s}$, primer annealing at $54,56,60,56$ and $62{ }^{\circ} \mathrm{C}$ for cagA, iceA, $\operatorname{dup} A, v a c A$ (s1/s2, s1a, s1b, s1c, m1, m2 and i1, i2) and oip $A$, respectively, for $30 \mathrm{~s}$ and extension at $72{ }^{\circ} \mathrm{C}$ for $40 \mathrm{~s}$. All reactions were performed through 35 cycles. The final cycle included a final extension at $72{ }^{\circ} \mathrm{C}$ for $10 \mathrm{~min}$. The presence of the $\operatorname{cag} A$, iceA and $\operatorname{dup} A$ genes was determined by PCR as previously described $[9,23,30]$. The genotypes of $v a c A \mathrm{~s} 1 / \mathrm{s} 2, \mathrm{~s} 1 \mathrm{a}, \mathrm{s} 1 \mathrm{~b}, \mathrm{~s} 1 \mathrm{c}, \mathrm{m} 1, \mathrm{~m} 2$ and $\mathrm{i} 1$, i2 were also determined by PCR as previously described $[6,16,29,37]$. The oipA gene was detected by PCR, which was additionally sequenced in order to define its functional status as either "on" or "off". The signal sequences of oipA gene including the CT repeats were amplified by using primer pairs as described previously [25]. The primers used to amplify the targeted genes were summarized in Table 5. The amplified products were analyzed in $1 \%$ agarose gel containing $1 \times \mathrm{TAE}$, stained with GelStain and visualized by electrophoresis at $110 \mathrm{~V}$ for $30 \mathrm{~min}$ using the gel documentation system (Bio-Rad, USA).

\section{Sequencing and bioinformatics analysis}

Positive PCR products were sent to the Beijing Genomics Institute (BGI) for purification and sequencing. The nucleotide sequences of the $\operatorname{cag} A$ 3' variable region and oipA were submitted to China National Microbiological Data Center. The accession numbers are NMDCN0000M60 to NMDCN0000ME4 and NMDCN0000ME5 to NMDCN0000MLM, respectively. DNA
Table 5 Primers used for PCR amplification of cagA, vacA, iceA, oipA and dupA genes

\begin{tabular}{|c|c|c|c|}
\hline Gene & Primer & Primer sequence $\left(5^{\prime}-3^{\prime}\right)$ & Product size (bp) \\
\hline \multirow[t]{2}{*}{$\operatorname{cag} A$} & $\operatorname{cagA3} 3^{\prime}-\mathrm{F}$ & TGCGTGTGTGGCTGTTAGTAG & $593-752$ \\
\hline & $\operatorname{cag} A 3^{\prime}-R$ & CCTAGTCGGTAATGGGTTGT & \\
\hline \multicolumn{4}{|l|}{$\operatorname{vac} A$} \\
\hline \multirow[t]{2}{*}{$\begin{array}{l}\mathrm{s} 1 / \\
\mathrm{s} 2\end{array}$} & Vs-F & ATGGAAATACAACAAACACAC & $259 / 286$ \\
\hline & VA-R & CTGCTTGAATGCGCCAAAC & \\
\hline \multirow[t]{2}{*}{ s1a } & Vs1a-F & GTCAGCATCACACCGCAAC & 190 \\
\hline & VA-R & CTGCTTGAATGCGCCAAAC & \\
\hline \multirow[t]{2}{*}{$\mathrm{s} 1 \mathrm{~b}$} & Vs $1 b-F$ & AGCGCCATACCGCAAGAG & 187 \\
\hline & VA-R & CTGCTTGAATGCGCCAAAC & \\
\hline \multirow[t]{2}{*}{ s1c } & Vs1c-F & CTCTCGCTTTAGTGGGGYT & 213 \\
\hline & VA-R & CTGCTTGAATGCGCCAAAC & \\
\hline \multirow[t]{2}{*}{ m1 } & $V m 1-F$ & GGCCCCAATGCAGTCATGGAT & 240 \\
\hline & $V m 1-R$ & GCTGTTAGTGCCTAAAGAAGCAT & \\
\hline \multirow[t]{2}{*}{ m2 } & $V m 2-F$ & GGAGCCCCAGGAAACATTG & 352 \\
\hline & $V m 2-R$ & CATAACTAGCGCCTTGCAC & \\
\hline \multirow[t]{2}{*}{ ¡1 } & $\mathrm{Vi}-\mathrm{F}$ & GTTGGGATTGGGGGAATGCCG & 495 \\
\hline & Vi1-R & TTAATTTAACGCTGTTTGAAG & \\
\hline \multirow[t]{2}{*}{$\mathrm{i} 2$} & Vi-F & GTTGGGATTGGGGGAATGCCG & 495 \\
\hline & Vi2-R & GATCAACGCTCTGATTTGA & \\
\hline \multirow[t]{2}{*}{ iceA1 } & iceA1-F & GTGTTTTTAACCAAAGTATC & 246 \\
\hline & iceA1-R & CTATAGCCAGTCTCTTTGCA & \\
\hline \multirow[t]{2}{*}{ iceA2 } & iceA2-F & GTTGGGTATATCACAATTTAT & 229 \\
\hline & iceA2-R & TTGCCCTATTTTCTAGTAGGT & \\
\hline \multirow[t]{2}{*}{ oipA } & oipA-F & CGCGGAAAGGAACGGGTTTT & 519 \\
\hline & oipA-R & TTAGCGTCTAGCGTTCTGCC & \\
\hline \multirow[t]{2}{*}{$\operatorname{dup} A$} & dupA-F & GACGATTGAGCGATGGGAATAT & 971 \\
\hline & dupA-R & CTGAGAAGCCTTATTATCTTGTTGG & \\
\hline
\end{tabular}

sequences were edited by EditPlus version 5.3.0 and the edited nucleotide sequences were subjected to translation using BioEdit version 7.2.5. The EPIYA segment types of CagA were analyzed using the program WebLogo 3 (http://weblogo.threeplusone.com/). Neighbor-Joining phylogenetic tree was constructed from $\operatorname{cagA} 3$ ' variable region nucleotide sequences using MEGA version 7.0.18 and bootstrap analysis was performed with 1000 replications. The Western strain 26695 (GenBank No. CP003904) and the East Asian strain GZ27 (GenBank No. KR154756) were used as reference sequences.

\section{Statistical analysis}

Statistical data were analyzed by SPSS software version 20. The chi-square test and Fisher's exact test were used to assess the relationship between specific genotype and geographic origins and clinical outcomes. P-value $<0.05$ was considered of a statistically significant difference. 


\section{Abbreviations}

H. pylori: Helicobacter pylori; PCR: Polymerase chain reaction; GC: Gastric carcinoma; PUD: Peptic ulcer disease; NUD: Non-ulcer dyspepsia; MALT: Mucosal-associated lymphoid tissue; cagA: Cytotoxin-associated gene A; vacA: Vacuolating cytotoxin A; iceA: Induced by contact with epithelium; oipA: Outer inflammatory protein $\mathrm{A}$; dupA: Duodenal ulcer promoting gene A.

\section{Supplementary Information}

The online version contains supplementary material available at https://doi. org/10.1186/s13099-021-00434-4.

Additional file 1: The phylogenetic tree of cagA gene.

\section{Acknowledgements}

Not applicable.

\section{Authors' contributions}

ZX and HY developed the idea, designed the study, analyzed the data and drafted the manuscript. DS, XS, XD, CY and CS collected the samples. LH, YY, $Y G, D F$ and LS performed the DNA extraction. $X H$ and RF analyzed the data, $M Z$ and $X Y$ designed the study and analyzed the results. JQ and JZ designed the study, reviewed and revised the manuscript. All authors read and approved the final manuscript.

\section{Funding}

This work was supported by the Health Research and Special Projects Grant of China (No. 201002020, No.201502005) and the National Science and Technology Major Project of China (2018ZX10712-001).

\section{Availability of data and materials}

The Western strain 26695 and East Asian strain GZ27 were downloaded from NCBI (https://www.ncbi.nlm.nih.gov/).

\section{Declarations}

\section{Ethics approval and consent to participate}

Not applicable.

\section{Consent for publication}

Full consent is given for publication in Gut Pathogens.

\section{Competing interests}

The authors declare that they have no competing interests.

\section{Author details}

${ }^{1}$ State Key Laboratory of Infectious Disease Prevention and Control, Collaborative Innovation Center for Diagnosis and Treatment of Infectious Diseases, Chinese Center for Disease Control and Prevention, National Institute for Communicable Disease Control and Prevention, Beijing, China. ${ }^{2}$ Peking Union Medical College Hospital, Peking Union Medical College, Chinese Academy of Medical Sciences, Beijing, China. ${ }^{3}$ The Second Nanning People's Hospital, Nanning, Guangxi Zhuang Autonomous Region, Nanning, China. ${ }^{4}$ Department of Gastroenterology, Rushan People's Hospital, Rushan, Shandong, China. ${ }^{5}$ Yiyang Central Hospital, Yiyang, Hunan, China. ${ }^{6}$ The First Affiliated Hospital of Jiamusi Medical University, Jiamusi, Heilongjiang, China. ${ }^{7}$ The People's Hospital of Huzhu Tu Ethnic Autonomous County, Haidong, Qinghai, China.

Received: 22 December 2020 Accepted: 7 June 2021 Published online: 15 June 2021

\section{References}

1. Adrian J, Bonsignore P, Hammer S, Frickey T, Hauck CR. Adaptation to host-specific bacterial pathogens drives rapid evolution of a human innate immune receptor. Curr Biol. 2019;29(4):616-30.
2. Alam J, Sarkar A, Karmakar BC, Ganguly M, Paul S, Mukhopadhyay AK. Novel virulence factor dupA of Helicobacter pylori as an important risk determinant for disease manifestation: An overview. World J Gastroenterol. 2020;26(32):4739-52.

3. Ansari S, Yamaoka Y. Helicobacter pylori virulence factors exploiting gastric colonization and its pathogenicity. Toxins. 2019;11(11):677-83.

4. Argent $\mathrm{RH}$, Burette $\mathrm{A}$, Miendje VY, Atherton JC. The presence of dupA in Helicobacter pylori is not significantly associated with duodenal ulceration in Belgium, South Africa, China, or North America. Clin Infect Dis. 2007;45(9):1204-6.

5. Assumpcao MB, Martins LC, Barbosa M, Antonia K, Santos D, Sintia B, et al. Helicobacter pylori in dental plaque and stomach of patients from Northern Brazil. World J Gastroenterol. 2010;16(4):3033-9.

6. Atherton JC, Cao P, Peek RM Jr, Tummuru MK, Blaser MJ, Cover TL. Mosaicism in vacuolating cytotoxin alleles of Helicobacter pylori. Association of specific vacA types with cytotoxin production and peptic ulceration. J Biol Chem. 1995;270(30):17771-7.

7. Blaser MJ. Intrastrain differences in Helicobacter pylori: a key question in mucosal damage? Ann Med. 1995;27(5):559-63.

8. Chauhan N, Tay ACY, Marshall BJ, Jain U. Helicobacter pylori vacA, a distinct toxin exerts diverse functionalities in numerous cells: an overview. Helicobacter. 2019;24(1):e12544

9. Chen CY, Wang FY, Wan HJ, Jin XX, Wei J, Wang ZK, et al. Amino acid polymorphisms flanking the EPIYA-A motif of Helicobacter pylori CagA C-terminal region is associated with gastric cancer in east China: experience from a single center. J Dig Dis. 2013;14(7):358-65.

10. Chen W, Zheng R, Zhang S, Zeng H, Xia C, Zuo T, Yang Z, Zou X, He J. Cancer incidence and mortality in China, 2013. Cancer Lett. 2017:401(4):63-71.

11. Chomvarin C, Namwat W, Chaicumpar K, Mairiang P, Sangchan A, Sripa $B$, et al. Prevalence of Helicobacter pylori vacA, cagA, cagE, iceA and babA2 genotypes in Thai dyspeptic patients. Int J Infect Dis. 2008;12(5):30-6.

12. Chung C, Olivares A, Torres E, Yilmaz O, Cohen H, Perez-Perez G. Diversity of vacA intermediate region among Helicobacter pylori strains from several regions of the world. J Clin Microbiol. 2010;48(3):690-6.

13. Ciara U, Rainer H. vacA's induction of vacA-containing vacuoles (VCVs) and their immunomodulatory activities on human $T$ cells. Toxins. 2016;8(6):190-4.

14. Doorn LJ, Figueiredo C, Francis M, Pena S, Quint WGV. Geographic distribution of vacA allelic types of Helicobacter pylori. Gastroenterol. 1999;116(4):823-30.

15. Doorn LJ, Figueiredo C, Sanna R, Plaisier A, Quint W. Clinical relevance of the cagA, vacA, and iceA status of Helicobacter pylori. Gastroenterol. 1998;115(1):58-62.

16. Falush D, Wirth T, Linz B, Pritchard JK, Stephens M, Kidd M, et al. Traces of human migrations in Helicobacter pylori populations. Science. 2003;299(5612):1582-5.

17. Ferreira RM, Machado JC, Letley D, Atherton JC, Pardo ML, Gonzalez CA, et al. A novel method for genotyping the Helicobacter pylori vacA intermediate region directly in gastric biopsy specimens. J Clin Microbiol. 2012;50(12):3983-9.

18. Gatti LL, Módena JL, Payão SL, Smith Mde A, Fukuhara Y, Módena JL, et al. Prevalence of Helicobacter pylori cagA, iceA and babA2 alleles in Brazilian patients with upper gastrointestinal diseases. Acta Trop. 2006;100(3):232-40.

19. González CA, Figueiredo C, Lic CB, Ferreira RM, Pardo ML, Ruiz Liso $J M$, et al. Helicobacter pylori cagA and vacA genotypes as predictors of progression of gastric preneoplastic lesions: a long-term follow-up in a high-risk area in Spain. Am J Gastroenterol. 2011;106(5):867-74

20. Hatakeyama M. Anthropological and clinical implications for the structural diversity of the Helicobacter pylori CagA oncoprotein. Cancer Sci. 2011;102(9):36-43.

21. Hooi JKY, Lai WY, Ng WK, Suen MMY, Underwood FE, Tanyingoh D, et al. Global prevalence of Helicobacter pylori infection: systematic review and meta-analysis. Gastroenterol. 2017;23(4):420-9.

22. Huang X, Deng Z, Zhang Q, Li W, Wang B, Li M. Relationship between the iceA gene of Helicobacter pylori and clinical outcomes. Ther Clin Risk Manag. 2016;12(2):1085-92.

23. Peek RM Jr, Thompson SA, Donahue JP, Tham KT, Atherton JC, Blaser $\mathrm{MJ}$, et al. Adherence to gastric epithelial cells induces expression of a 
Helicobacter pylori gene iceA, that is associated with clinical outcome. P Assoc Am Physician. 1998;1 10(6):531-44.

24. Kao CY, Sheu BS, Wu JJ. Helicobacter pylori infection: an overview of bacterial virulence factors and pathogenesis. Biomed J. 2016;39(1):14-23.

25. Kauser F, Hussain MA, Ahmed I, Ahmad N, Habeeb A, Khan AA, et al, Comparing genomes of Helicobacter pylori strains from the high-altitude desert of Ladakh, India. J Clin Microbiol. 2005;43(4):1538-45.

26. Kim JY, Kim N, Nam RH, Suh JH, Chang H, Lee JW, et al. Association of polymorphisms in virulence factor of Helicobacter pylori and gastroduodenal diseases in South Korea. J Gastroenterol Hepatol. 2014;29(5):984-91.

27. Kim SY, Woo CW, Lee YM, Son BR, Kim JW, Chae HB, et al. Genotyping cagA, vacA subtype, iceA1, and babA of Helicobacter pylori isolates from Korean patients, and their association with gastroduodenal diseases. J Korean Med Sci. 2001;16(4):579-84.

28. Li WQ, Zhang JY, Ma JL, Li ZX, Zhang L, Zhang Y, et al. Effects of Helicobacter pylori treatment and vitamin and garlic supplementation on gastric cancer incidence and mortality: follow-up of a randomized intervention trial. BMJ. 2019;366(2):15016.

29. Liao YL, Guo G, Mao XH, Xie QH, Zhang WJ, Liu XF, et al. Core genome haplotype diversity and vacA allelic heterogeneity of Chinese Helicobacter pylori strains. Curr Microbiol. 2009;59(2):123-9.

30. Lu H, Hsu PI, Graham DY, Yamaoka Y. Duodenal ulcer promoting gene of Helicobacter pylori. Gastroenterol. 2005;128(4):833-48.

31. Matos Jl, de Sousa HA, Marcos-Pinto R, Dinis-Ribeiro M. Helicobacter pylori cagA and vacA genotypes and gastric phenotype: a meta-analysis. Eur J Gastroenterol Hepatol. 2013;25(12):1431-41.

32. Memon AA, Hussein NR, Miendje Deyi VY, Burette A, Atherton JC. Vacuolating cytotoxin genotypes are strong markers of gastric cancer and duodenal ulcer-associated Helicobacter pylori strains: a matched casecontrol study. J Clin Microbiol. 2014;52(8):2984-9.

33. Momenah AM, Tayeb MT. Relationship between Helicobacter pylori vacA genotypes status and risk of peptic ulcer in Saudi patients. Saudi Med J. 2006;27(6):804-7.

34. Pan ZJ, Berg DE, van der Hulst RW, Su WW, Raudonikiene A, Xiao SD, et al. Prevalence of vacuolating cytotoxin production and distribution of distinct vacA alleles in Helicobacter pylori from China. J Infect Dis. 1998;178(1):220-6.

35. Podzorski RP, Podzorski DS, Wuerth A, Tolia V. Analysis of the vacA, cagA, cagE, iceA, and babA2 genes in Helicobacter pylori from sixty-one pediatric patients from the Midwestern United States. Diagn Microbiol Infect Dis. 2003;46(9):83-8.

36. Reva I, Takano T, Higuchi W, I wao Y, Taneike I, Nakagawa S, et al. Virulence genotypes and drug resistance of Helicobacter pylori from Vladivostok, Russia: another feature in the Far East. Microbiol Immunol. 2012;56(3):198-202.

37. Rhead JL, Letley DP, Mohammadi M, Hussein N, Mohagheghi MA, Eshagh $\mathrm{HM}$, et al. A new Helicobacter pylori vacuolating cytotoxin determinant, the intermediate region, is associated with gastric cancer. Gastroenterology. 2007;133(3):926-36.

38. Sheikh AF, Yadyad MJ, Goodarzi H, Hashemi SJ, Aslani S, Assarzadegan MA, et al. cagA and vacA allelic combination of Helicobacter pylori in gastroduodenal disorders. Microb Pathog. 2018;122(34):144-50.

39. Shiota S, Matsunari O, Watada M, Hanada K, Yamaoka Y. Systematic review and meta-analysis: the relationship between the Helicobacter pylori dupA gene and clinical outcomes. Gut Pathog. 2010;2(1):13-7.

40. Sterbenc A, Jarc E, Poljak M, Homan M. Helicobacter pylori virulence genes. World J Gastroenterol. 2019;25(33):4870-84.

41. Sukri A, Hanafiah A, Mohamad ZN, Kosai NR. Epidemiology and role of Helicobacter pylori virulence factors in gastric cancer carcinogenesis. APMIS. 2020;128(2):150-61.

42. Tserentogtokh T, Gantuya B, Subsomwong P, Oyuntsetseg K, Bolor D, Erdene-Ochir Y, et al. Western-type Helicobacter pylori CagA are the most frequent type in Mongolian patients. Cancers. 2019;11(5):725-9.

43. Wang J, van Doorn LJ, Robinson PA, Ji X, Wang D, Wang Y, et al. Regional variation among vacA alleles of Helicobacter pylori in China. J Clin Microbiol. 2003;41(5):1942-5.

44. Wei GC, Chen J, Liu AY, Zhang M, Liu XJ, Liu D, et al. Prevalence of Helicobacter pylori vacA, cagA and iceA genotypes and correlation with clinical outcome. Exp Ther Med. 2012;4(6):1039-44.

45. Yamaoka Y, Kwon DH, Graham DY. A M(r) 34,000 proinflammatory outer membrane protein (oipA) of Helicobacter pylori. Proc Natl Acad Sci USA. 2000;97(13):7533-8.

46. Yamaoka Y. Helicobacter pylori outer membrane proteins and gastroduodenal disease. Gut. 2006;55(6):775-81.

47. Yamaoka Y. Relationship between Helicobacter pylori iceA, cagA, and vacA status and clinical outcome: studies in four different countries. J Clin Microbiol. 1999;37(7):2274-9.

48. Yang H, Wu SV, Pichuantes S, Song M, Wang J, Zhou D, et al. High prevalence of cagA-positive strains in Helicobacter pylori-infected, healthy, young Chinese adults. J Gastroenterol Hepatol. 1999;14(5):476-80.

49. Zhao Q, Song C, Wang K, Li D, Yang Y, Liu D, et al. Prevalence of Helicobacter pylori babA, oipA, sabA, and homB genes in isolates from Chinese patients with different gastroduodenal diseases. Med Microbiol Immunol. 2020;209(5):565-77.

50. Zheng PY, Hua J, Yeoh KG, Ho B. Association of peptic ulcer with increased expression of Lewis antigens but not cagA, iceA, and vacA in Helicobacter pylori isolates in an Asian population. Gut. 2000;47(1):18-22.

\section{Publisher's Note}

Springer Nature remains neutral with regard to jurisdictional claims in published maps and institutional affiliations.

Ready to submit your research? Choose BMC and benefit from:

- fast, convenient online submission

- thorough peer review by experienced researchers in your field

- rapid publication on acceptance

- support for research data, including large and complex data types

- gold Open Access which fosters wider collaboration and increased citations

- maximum visibility for your research: over $100 \mathrm{M}$ website views per year

At BMC, research is always in progress.

Learn more biomedcentral.com/submissions 